\title{
Flora da Bahia: Leguminosae - Parapiptadenia (Mimosoideae: Mimoseae)
}

\author{
Pétala Gomes Ribeiro $^{1^{*}}$, Luciano Paganucci de Queiroz $^{1, \mathrm{a}} \&$ Marli Pires Morim ${ }^{2, \mathrm{~b}}$ \\ ${ }^{1}$ Programa de Pós-Graduação em Botânica, Departamento de Ciências Biológicas, Universidade Estadual de \\ Feira de Santana, Feira de Santana, Bahia, Brasil. \\ 2 Instituto de Pesquisas Jardim Botânico do Rio de Janeiro, Rio de Janeiro, RJ, Brasil.
}

\begin{abstract}
Resumo - É apresentado o tratamento taxonômico do gênero Parapiptadenia (4 espécies) no estado da Bahia, Brasil. São apresentados uma chave de identificação, descrições morfológicas, comentários taxonômicos, ilustrações e mapas de distribuição geográfica das espécies na Bahia.
\end{abstract}

Palavras-chave adicionais: florística, "grupo Piptadenia", Parapiptadenia, taxonomia.

\begin{abstract}
Flora of Bahia: Leguminosae - Parapiptadenia (Mimosoideae: Mimoseae)) - The taxonomic treatment of the genus Parapiptadenia (4 species) from the state of Bahia, Brazil, is presented. An identification key, morphological descriptions, taxonomic comments, illustrations and distribution maps of the species in Bahia are presented.
\end{abstract}

Additional key words: floristics, Parapiptadenia, "Piptadenia group", taxonomy.

Leguminosae é a terceira maior família de plantas, com cerca de 770 gêneros e 19.327 espécies, e possui distribuição cosmopolita (Schrire et al. 2005; LPWG 2013). Pode ser reconhecida pela combinação de folhas alternas, compostas, com estípulas, e flores pentâmeras, períginas ou hipóginas, diclamídeas, diplostêmones, com ovário súpero unicarpelar, unilocular, com óvulos inseridos alternadamente em uma placenta marginal (Queiroz 2009). O nome "Leguminosae" remete ao tipo de fruto mais típico na família, o legume; entretanto, existe uma variação considerável de tipos de frutos em Leguminosae, desde folículos, frutos indeiscentes, legumes bacáceos a drupas, frutos alados ou sâmaras, frutos articulados, como o lomento, dentre outros (Queiroz 2009). Apresentam grande importância econômica, incluindo diversas monoculturas, como soja, feijão, ervilha e amendoim, dentre outros produtos utilizados na alimentação humana e animal. Algumas espécies também são muito utilizadas como fornecedoras de madeira para construção, fontes de produtos farmacêuticos e medicinais, artesanato, essências para perfumes e tinturas. Além disso, são utilizadas na arborização das cidades, no paisagismo, na fabricação de papel, na indústria têxtil, também como fontes de fertilizantes e outros produtos químicos, bem como em rituais religiosos (Lewis et al. 2005; Queiroz 2009).

Leguminosae é a família com maior número de espécies no Brasil, abrangendo cerca de 2.800 espécies, sendo 1.507 endêmicas, o que corresponde a 54,7\% das espécies de angiospermas endêmicas do país (BFG 2015). Juntamente com outras famílias

\footnotetext{
*Autora para correspondência: petalagribeiro@gmail.com;

aluciano.paganucci@gmail.com; ${ }^{b}$ mpires@jbrj.gov.br

Editor responsável: Alessandro Rapini

Submetido: 1 junho 2016; aceito: 13 out. 2016

Publicação eletrônica: 1 nov. 2016; versão final: 7 nov. 2016

Apêndice: Lista completa de material examinado
}

(Orchidaceae, Asteraceae, Rubiaceae, Melastomataceae, Bromeliaceae, Poaceae, Myrtaceae, Euphorbiaceae e Malvaceae), as leguminosas contribuem com 47,2\% (15.404) das espécies de angiospermas do Brasil (BFG 2015). Estão representadas em diversos ambientes, com os mais variados hábitos, de ervas, lianas e arbustos a grandes árvores. $\mathrm{O}$ sucesso adaptativo da família se deve em grande parte à associação com bactérias fixadoras de nitrogênio em nódulos das raízes. Essa associação permite às leguminosas ocuparem solos pobres em nitrogênio (Queiroz 2009). A família está bem representada na Bahia, com cerca de 925 espécies, sendo este o estado com o maior número de espécies de Leguminosae depois de Minas Gerias (BFG 2015). Dada a sua grande diversidade, estão sendo preparados tratamentos menos inclusivos para as Leguminosas da flora da Bahia, e damos aqui continuidade aos tratamentos iniciados no estado com as monografias da Aliança Chloroleucon (Mimosoideae: Ingeae) (Almeida et. al. 2015) e dos gêneros Canavalia (Papilionoideae: Diocleae; Snack \& Queiroz 2016) e Hymenaea (Caesalpinioideae: Detarieae; Souza et al. 2016).

Tradicionalmente, Leguminosae é dividida em três subfamílias: Caesalpiniodeae (ca. 2250 espécies e 4 tribos), Mimosoideae (ca. 3.270 espécies e 4 tribos) e Papilionoideae (ca. 13800 espécies e 28 tribos). A família é sustentada como monofilética baseado em trabalhos de filogenia com dados morfológicos e moleculares (Lewis et al. 2005; Queiroz 2009). Papilionoiodeae e Mimosoideae (excluindo Dinizia) emergem como grupos monofiléticos aninhados em Caesalpiniodeae, que portanto não constitui um grupo monofilético (Luckow et al. 2003; Wojciechowski et al. 2004; Bruneau et al. 2008; Queiroz 2009; LPWG 2013). Dessa maneira, uma nova proposta de classificação para as Leguminosas está sendo proposta. A família passará de três para seis subfamílias fortemente sustentadas como monofiléticas: 
Ceasalpiniodeae, Cercidoideae, Detarioideae, Dialioideae, Duparquetioideae e Papilionoideae (LPWG, in prep.). Nesta classificação, a subfamília Mimosoideae passa a ser representada pelo clado Mimosoida, aninhado na recircunscrita Caesalpinioideae. É neste clado Mimosoida que se encontra o gênero Parapiptadenia. Como esta proposta ainda não está publicada, no entanto, adotamos aqui a classificação tradicional, considerando Parapiptadenia na subfamília Mimosoideae.

\section{Parapiptadenia Brenan}

Árvores ou arbustos; ramos inermes, sem costelas. Estípulas presentes ou não. Folhas bipinadas; pecíolo e raque com seção transversal cilíndrica, sulcados; pinas 1-7 pares; parafilídios e espículas interpinas ausentes, prolongamento terminal da raque $1-4 \mathrm{~mm}$ compr.; folíolos 2-21 pares, opostos, os distais geralmente mais largos, papiráceos, elípticos a elíptico-oblongos, ápice arredondado a obtuso, base assimétrica, oblíqua, margem reta, glabros ou com tricomas esparsos em ambas as faces; venação peninérvea, nervura central subcêntrica ou oblíqua; nectários extraflorais sésseis, discoides, cilíndricos, oblongos ou cônicos, ao longo do pecíolo, na raque (geralmente entre o último par de pinas distais) e nas pinas (entre os pares de folíolos distais, geralmente o último). Inflorescências em espigas, fasciculadas, geminadas ou isoladas, axilares ou supraxilares, ramifloras; brácteas florais ovallanceoladas, côncavas, acuminadas, glabras a indumentadas, persistentes ou tardiamente caducas; botões florais obovoides ou elipsoides. Flores 5-meras, bissexuadas, sésseis; cálice campanulado, lacínias curtas, agudas; corola cilíndrica ou campanulada, tubo curto, incluso no cálice, lacínias eretas, glabras; estames 10, vináceos, raramente amarelo-ouro, filetes levemente concrescidos na base, equilongos, anteras elipsoides, com glândula arredondada, subséssil a brevemente estipitada (estípite visível no dorso da antera), geralmente caduca; ovário glabro, estipitado, exserto à corola, estigma punctiforme. Legumes estipitados, compressos, margem levemente espessada, sinuosa, ápice acuminado; valvas rígido-coriáceas, onduladas, glabras. Sementes plano-compressas, aladas, testa membranácea, castanho-amarronzada; embrião com cotilédones planos.

Na Bahia, a tribo Mimoseae (sensu Luckow 2005) está representada por 11 gêneros, sendo parte deles (6) pertencentes ao "grupo Piptadenia" (Lewis \& Elias 1981) [Anadenanthera Speg., Parapiptadenia, Piptadenia Benth., Pityrocarpa (Benth.) Britton \& Rose, Pseudopiptadenia Rauschert e Stryphnodendron Mart.]. Parapiptadenia inclui seis espécies do leste do Brasil, da Paraíba ao Rio Grande do Sul, sendo Parapiptadenia rigida (Benth.) Brenan presente também no Paraguai, Argentina e Uruguai (Lima \& Lima 1984). Lewis (1987) registrou três espécies do gênero para a Bahia e, posteriormente (Lewis 1994), descreveu Parapiptadenia ilheusana G.P.Lewis.
Assim, a Bahia abriga quatro das cinco espécies de Parapiptadenia representadas no Brasil (BFG 2015). O gênero é reconhecido por uma combinação de caracteres que inclui folhas com relativamente poucos folíolos (2-21 pares por pina), estames geralmente vináceos (exceto $P$. ilheusana) e legumes com valvas onduladas (Figura 1).

\section{Chave para as espécies}

1. Folhas com até 2 pares de pinas.

2. Folíolos 2-4 pares por pina, os medianos obovais, base e ápice arredondados, nervura principal central a ligeiramente subcentral; nectário plano, localizado da porção basal à distal do pecíolo; filetes vináceos 1. P. blanchetii

2'. Folíolos 6-12 pares por pina, oblongos, base truncada, ápice falcado, nervura principal oblíqua; nectário cônico, localizado entre o par de pinas basal; filetes amarelo-ouro

\section{P. ilheusana}

1'. Folhas com mais de 2 pares de pinas.

3. Raque foliar, folíolos e eixo da inflorescência indumentados; nectário inconspícuo (visível apenas com auxílio de lupa), localizado da porção basal à distal do pecíolo, mas geralmente na porção mediana 3. P. pterosperma

3'. Raque foliar, folíolos e eixo da inflorescência glabros, ou indumento restrito apenas a um tufo de tricomas próximo à base dos folíolos, na face abaxial; nectário conspícuo, de forma variável, localizado na base do pecíolo, próximo ao pulvino, ou entre o par de pinas basal.

4. Nectário peciolar oblongo (plano ou côncavo), localizado na base do pecíolo, acima do pulvino ou abaixo do meio do pecíolo; folíolos com nervura principal central e ápice arredondado ou obtuso; filetes vináceos; encontrada na Caatinga ......... 4. P. zehntneri

4'. Nectário cônico, localizado entre o par basal de pinas; folíolos com nervura principal oblíqua e ápice falcado; filetes amarelo-ouro; encontrada na Mata Atlântica

2. P. ilheusana

1. Parapiptadenia blanchetii (Benth.) Vaz \& M.P.Lima, Rodriguésia 32(55): 37.1980. Piptadenia blanchetii Benth., Trans. Linn. Soc. London 30: 371. 1875.

Figuras $1 \mathrm{~A}-\mathrm{C}, 2$ e 3.

Nomes populares: fava (Feira de Santana), faveiro (Amargosa, Cruz das Almas), fava-preta (Cruz das Almas), fava-cabocla (Amargosa, Inhambupe).

Arbusto a árvore 1-10 m alt. Estípulas não vistas. Pecíolo 14-45(-78) mm compr., pulvino 2-3 $\mathrm{mm}$ compr.; raque ca. $18 \mathrm{~mm}$ compr., glabra a esparsamente pubescente; nectário peciolar 4-7 × 11,3 $\mathrm{mm}$, discoide, plano, raramente cilíndrico, localizado da porção basal à distal do pecíolo, ligeiramente menores na raque e nas pinas; prolongamento terminal da raque $1-2(-3) \mathrm{mm}$ compr.; 

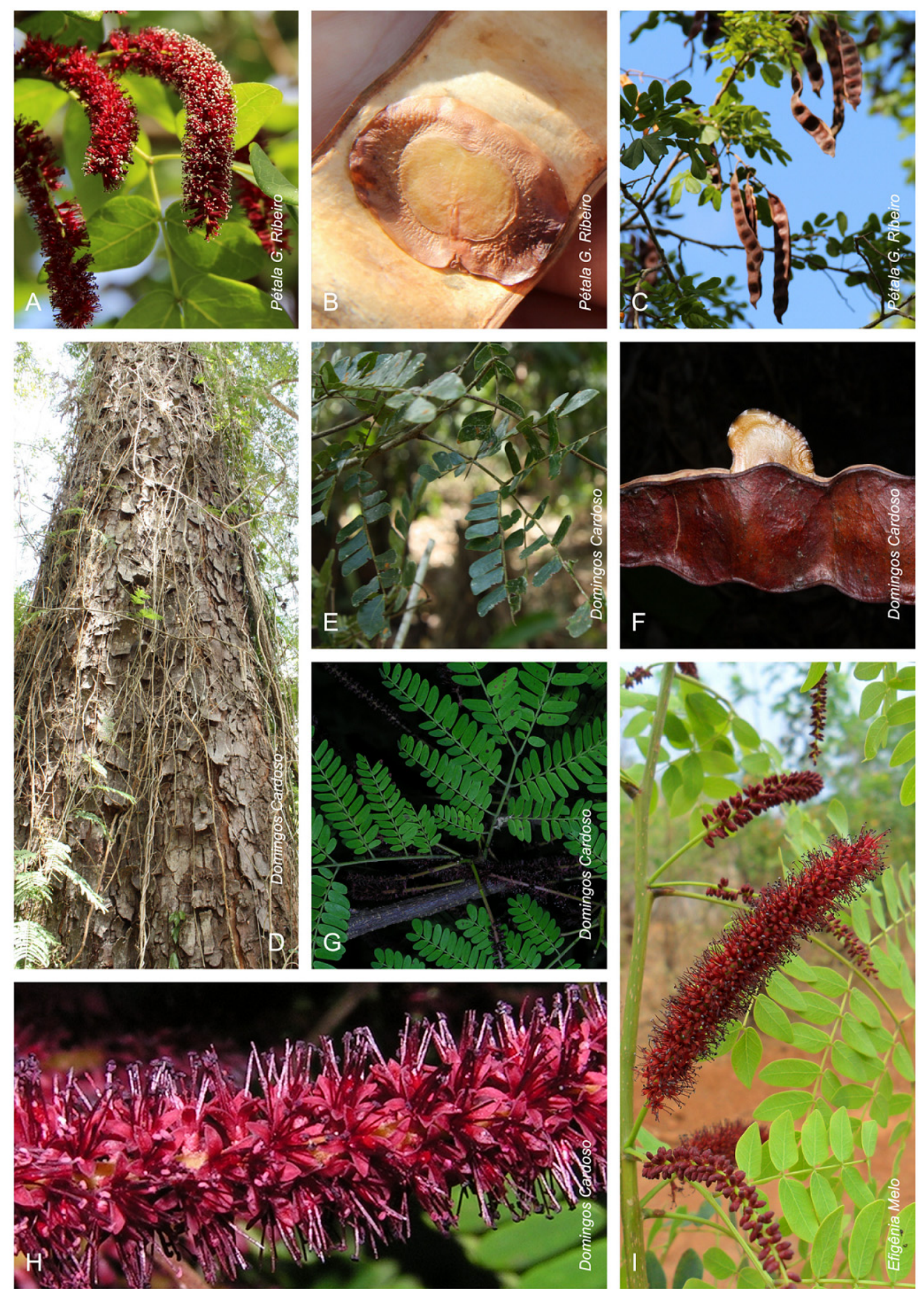

Figura 1. Caracteres morfológicos de Parapiptadenia. A-C. P. blanchetii: A- espigas; B- detalhe do legume aberto mostrando uma semente alada; C- ramo com legumes mostrando superfície valvar. D-F. P. ilheusana: D- tronco; E- folhas; F- detalhe do legume com uma semente alada saindo. G, H. P. pterosperma: G- folhas; H- detalhe da inflorescência com flores em antese. I. P. zehntneri: detalhe do ramo com folhas e inflorescências em flores e botões. (Fotos A-C- P.G. Ribeiro; D-H- D. Cardoso; I- E. Melo). 
pinas 1(2) pares, a basal 17-68(-120) mm compr., a distal 55-70 mm compr.; folíolos 2-4 pares, 21-60($70) \times(8-) 15-38(-46) \mathrm{mm}$, os medianos obovais, ápice arredondado, base assimétrica, nervura principal central a ligeiramente subcentral, margem lisa, ambas as faces reticuladas e glabras, exceto por um tufo de tricomas na base da face abaxial da lâmina. Espigas 33-80 × 6-8 mm, isoladas ou geminadas, axilares ou supraxilares; pedúnculo 8-35 mm compr., glabro; brácteas $0,5-1,2 \times$ ca. $0,3 \mathrm{~mm}$, lineares, ápice agudo, persistentes, glabras, margem serreada; botões elipsoides. Cálice 0,8-1 mm compr., lacínias ca. 0,2 mm compr., superfície externa glabra; corola 2,8-3 $\mathrm{mm}$ compr., cilíndrica, glabra, tubo $1-1,1 \mathrm{~mm}$ compr., lobos 1,8-2 mm compr.; filetes 3-5 mm compr., vináceos; ovário $0,8-1 \mathrm{~mm}$ compr., ca. 14-ovulado, estípite 1,8-2 $\mathrm{mm}$ compr., estilete 1-2 $\mathrm{mm}$ compr. Legumes $11-15,5 \times 2,3-4 \mathrm{~cm}$, estípite $1-2,3 \mathrm{~cm}$ compr. Sementes transverso-elípticas, núcleo seminífero 8-12 × 6-8 mm, ala 2-6 mm larg.

Conhecida apenas na Bahia. D7, D9, E8, E9, F8, H8: Caatinga (florestas estacionais deciduais e semideciduais, ocasionalmente em áreas antropizadas), em altitudes de 40-810 m. Floresce de julho a abril; frutifica de março a abril e de agosto a outubro.

Material selecionado - Amargosa, 26 mar. 1980 (fr.), G.C.P. Pinto 174 (CEPEC, HRB, IPA); Anguera, fazenda Retiro, ca. 18 $\mathrm{km}$ de Feira de Santana, na Estrada do Feijão sentido Ipirá, $12^{\circ} 09^{\prime} 42^{\prime \prime S}$, 39¹1'02"W, 300-600 m s.n.m., 22 maio 2007 (est.), D. Cardoso \& R.M. Santos 1918 e 1943 (HUEFS); Cachoeira, trecho superior do rio Jacuípe, vale dos rios Paraguaçu e Jacuípe, $12^{\circ} 32^{\prime} \mathrm{S}, 39^{\circ} 05^{\prime} \mathrm{W}, 40-120$ m s.n.m., fev. 1981 (bot., fl.), Grupo Pedra do Cavalo 1096 (ALCB, BAH, CEPEC, HRB, HUEFS, IPA); Conceição do Coité, Serra do Mucambo, $11^{\circ} 30^{\prime} \mathrm{S}, 30^{\circ} 12^{\prime} \mathrm{W}$, 15 fev. 2012 (bot., fl.), A.O. Matos \& D.N. Carvalho 15 (HUEFS). Cruz das Almas, dez. 1950 (bot., fl.), G.C.P. Pinto 644 (ALCB, BAH, RB); Dom Macedo Costa, fazenda Mocambo, 25 set. 1982 (bot. e fl.), M.J.S. Lemos 56 (HUEFS); Elísio Medrado, Recôncavo Sul, Serra da Jiboia, 12 $2^{\circ} 51^{\prime} \mathrm{S}, 39^{\circ} 28^{\prime} \mathrm{W}, 8$ fev. 2011 (est.), M.L. Guedes et al. 17940 (ALCB); Feira de Santana, rodovia Feira de Santana-Rio de Janeiro, $\mathrm{Km} 8$, na margem do rio Jacuípe, 19 fev. 1981 (bot. e fl.), A.M. Carvalho et al. 587 (CEPEC, HRB, RB); BA-052, 4 km W de Feira de Santana, $12^{\circ} 16^{\prime} 15^{\prime \prime} \mathrm{S}, 39^{\circ} 03^{\prime} 34^{\prime \prime} \mathrm{W}, 13$ nov. 1986 (bot.), L.P. Queiroz \& M.J.S. Lemos 1038 (HUEFS); Inhambupe, 3 jan. 1981 (bot. e fl.), G.C.P. Pinto 6 (CEPEC, HRB, HUEFS, IPA, MBM); Itaju do Colônia, 7,5 km SE da cidade, na estrada para Palmira, $15^{\circ} 09^{\prime} 13^{\prime \prime S}, 39^{\circ} 39^{\prime} 27,6^{\prime \prime W}$, ca. 250 m s.n.m., 19 mar. 2001 (fr.), W.W. Thomas et al. 12372 (CEPEC, HUEFS, RB); Itatim, Morro do Agenor ou da Madeira, $12^{\circ} 43^{\prime} \mathrm{S}, 3^{\circ} 42^{\prime} \mathrm{W}, 310-430 \mathrm{~m}$ s.n.m., 17 dez. 1995 (bot., fl.), E. Melo et al. 1410 (BAH, HUEFS, UB); Jacobina, ramal a ca. de $9 \mathrm{~km}$ na rodovia BA-052, $5 \mathrm{~km}$ ramal adentro para Riachão de Jacobina, 29 ago. 1990 (fr.), J.L. Hage et al. 2275 (CEPEC, HRB, HUEFS, MBM); Jequié, próximo a Jequié, 135'시"S, 39³8'37"W, 26 out.1978 (fr.), A.P.P. Araújo 123 (HRB, RB); Riachão do Jacuípe, fazenda Sossego, a ca. $11 \mathrm{~km} \mathrm{da}$ cidade, 12³2'S, 3905'W, 11 ago. 2002 (fr.), F.S. Silva 1 (HUEFS); Santa Terezinha, Serra da Jiboia, 555 m s.n.m., 20 fev.1998 (bot., fl.), F. França et al. 2486 (HUEFS); Vitória da Conquista, Hotel

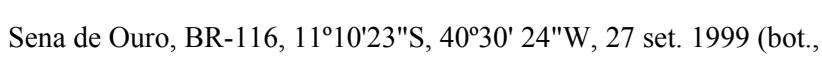
fl.), S.M. Faria et al. 1833 (RB); s.mun., 1831(fl.), L. Riedel 2106, com Luschnart 1831-1835 (NY); Serra da Jocobina, J.S. Blanchet 3295 (holótipo W, F, RB foto).

Parapiptadenia blanchetii se diferencia das demais espécies do gênero na Bahia por possuir geralmente um, raramente dois pares de pinas (vs. 2 ou mais pares de pinas nas demais espécies), pelo nectário discoide plano, conspícuo, no meio do pecíolo, e pelo tamanho dos folíolos, que pode chegar a $7 \mathrm{~cm}$ compr. Quando estéril, pode ser confundida com Piptadenia irwinii G.P.Lewis, por ambas apresentarem geralmente um par de pinas apenas, com folíolos de formato e tamanho semelhantes. Parapiptadenia blanchetii diferencia-se, no entanto, pelo nectário peciolar maior (4-7 $\mathrm{mm}$ compr. vs. 0,5-2 $\mathrm{mm}$ diam. em $P$. irwinii), e pela ausência de acúleos (presentes em $P$. irwinii), e quando fértil, também pelo tipo de sinflorescência (espigas axilares vs. espigas agrupadas em panículas), pelos estames vináceos (vs. amarelados), legumes com valvas rígido-coriáceas (vs. cartáceos) e sementes aladas (vs. não aladas).

2. Parapiptadenia ilheusana G.P.Lewis, Kew Bull. 49: 99. 1993.

Figuras 1D-F, 3 e 4A-E.

Nome popular: sucupiruçu (Ilhéus).

Árvore 3-18 m alt. Estípulas não vistas. Pecíolo 10-45 mm compr., pulvino 2-3 mm compr.; raque 18 $45 \mathrm{~mm}$ compr., glabra, segmentos interpinais 14-27 mm compr.; nectário peciolar cônico, localizado entre o par basal de pinas, ligeiramente menores na raque e nas pinas; prolongamento da raque $1-4 \mathrm{~mm}$ compr.; pinas 2 ou 3 pares, a basal 50-70 $\mathrm{mm}$ compr., a mediana 65-75 mm compr., a distal 75-115 mm compr.; folíolos da pina basal 6-9 pares, da mediana 8 ou 9 pares, da apical 9-12 pares, 20-23 × 7-10 mm, os medianos oblongos, base truncada, ápice falcado, nervura principal oblíqua, os distais mais largos, obovados, ápice arredondado, base assimétrica, truncada, margem lisa, ambas as faces glabras, com tricomas esparsos na base da nervura principal, ambas as superfícies reticuladas. Espigas 50-95 × 7-8 mm, isoladas ou geminadas, axilares; pedúnculo 22-25 mm compr., glabro; brácteas $0,3-0,4 \mathrm{~mm}$ compr., triangulares, côncavas, persistentes; botões obovoides. Cálice 1-1,2 mm compr., lacínias 0,2-0,3 mm compr., superfície externa pubescente; corola 2,8-3 $\mathrm{mm}$ compr., glabra, tubo 0,4-0,5 mm compr., lobos 2,5-3 mm compr.; filetes 3-4 mm compr., amarelo-ouro; ovário 1-1,2 mm compr., glabro, 16-ovulado, estípite $1,8-2 \mathrm{~mm}$ compr., estilete $2-2,3 \mathrm{~mm}$ compr. Legumes $11-21 \times 2,4-3,3 \mathrm{~cm}$, estípite 0,4-0,6 cm compr. Sementes transverso-elípticas, núcleo seminífero 25$28 \times 18-19 \mathrm{~mm}$, ala 2-4 mm larg.

Registrada apenas para o sul da Bahia. G8, G/H8: Mata Atlântica (floresta higrófila), a $50 \mathrm{~m}$ s.n.m. Floresce de outubro a dezembro e frutifica em outubro e abril. 


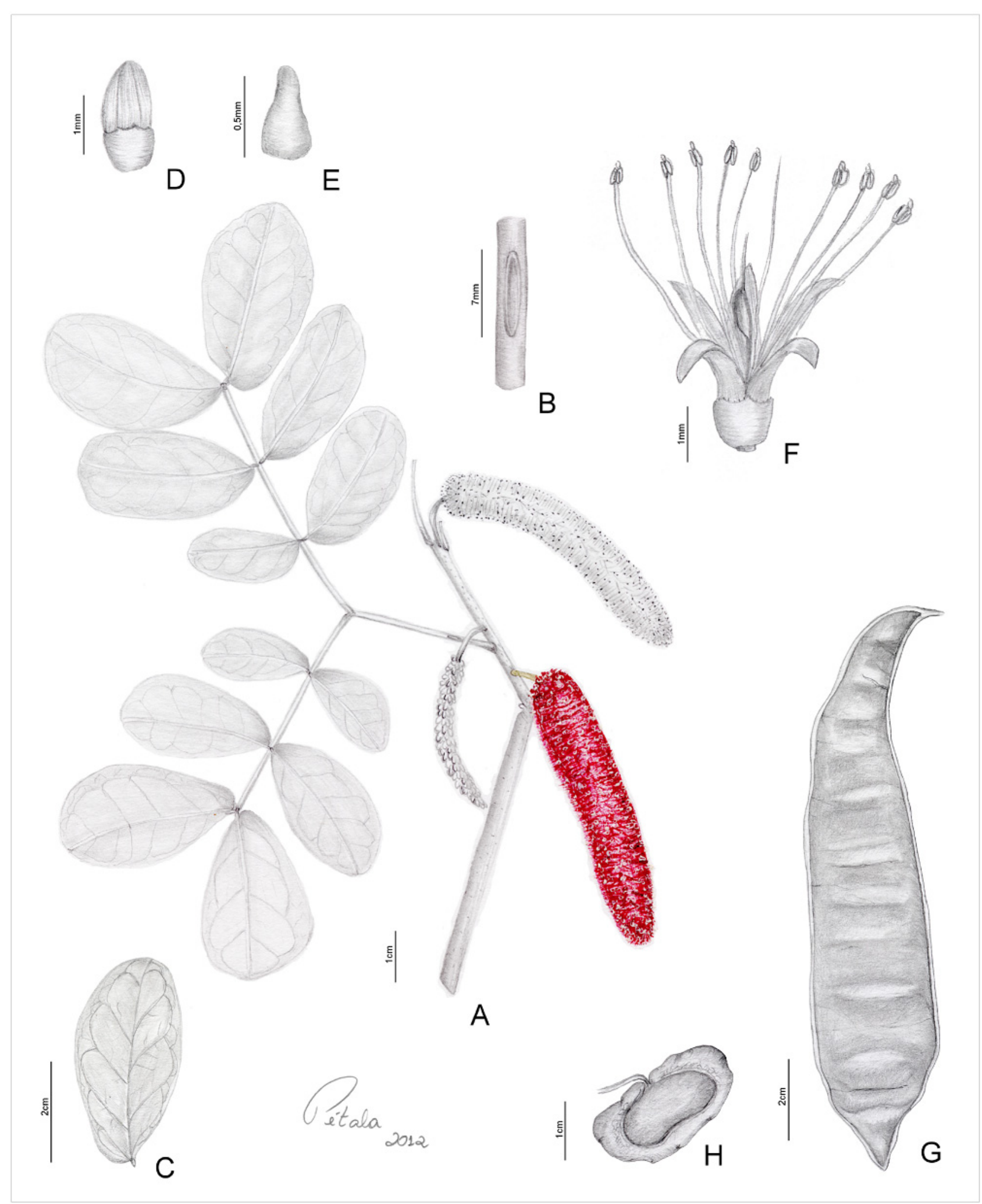

Figura 2. Parapiptadenia blanchetii: A- ramo com folha e inflorescências; B- nectário peciolar; C- folíolo mediano, face adaxial; D- botão floral; E- bráctea floral; F- flor; G- legume; H- semente alada (A-F- Lucca 16; G, H- Guedes 17769; por P.G. Ribeiro).

Material selecionado - Ilhéus, CEPEC, Quadra H', Km 22 da rodovia Ilhéus-Itabuna, BR-415, 18 dez. 1986 (fl.), T.S. Santos 4303 (holótipo CEPEC, isótipos ALCB, HRB, HUEFS, K, MBM, MBML, NY, RB, SP); Itaju do Colônia, fazenda Nova Esperança, ca. 13 km de Ibicaraí, 1456'59"S, 39³7'37"W, 2 out. 2008 (bot., fl., fr.), L.P. Queiroz et al. 13883 (HUEFS).
Parapiptadenia ilheusana diferencia-se das demais espécies do gênero na Bahia por possuir estames amarelo-ouro (vs. vináceos), pelos folíolos com nervura principal obliqua e ápice falcado (vs. central ou subcêntrica e ápice arredondado ou obtuso). Pode ser confundida com indivíduos de Pseudopiptadenia 


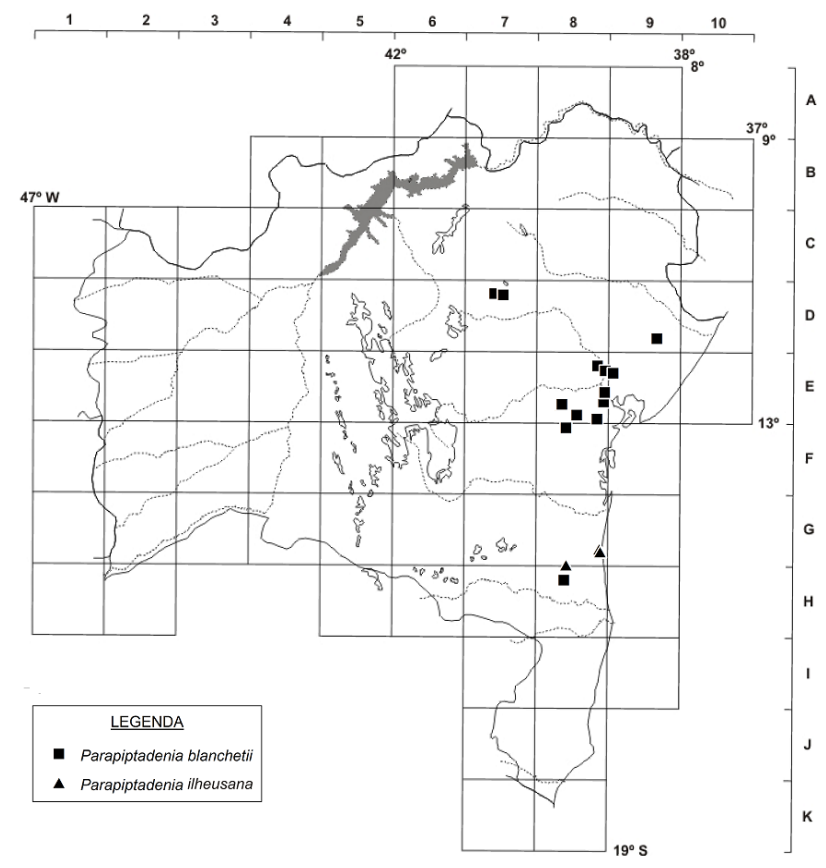

Figura 3. Mapa de distribuição de Parapiptadenia blanchetii e $P$. ilheusana no estado da Bahia.

bahiana G.P.Lewis \& M.P.Lima, quando com poucas pinas, por compartilharem a mesma forma falcada do ápice do folíolo e a coloração amarelada dos estames. Todavia, $P$. ilheusana diferencia-se daquela espécie pelo nectário cônico, localizado entre o par basal de pinas (vs. discoide e plano, localizado no meio do pecíolo, em Pseudopiptadenia bahiana), pelas flores com corola glabra (vs. pubescente) e pelos frutos do tipo legume (vs. folículo).

\section{Parapiptadenia pterosperma (Benth.) Brenan, Kew}

Bull. 17: 228. 1963. Piptadenia pterosperma Benth., J. Bot. (Hooker) 4: 338. 1841.

Figuras $1 \mathrm{G}, \mathrm{H}, 4 \mathrm{~F}, \mathrm{G}, 5$ e $6 \mathrm{H}$.

Nomes populares: angico-vermelho (Porto Seguro), viola (Ilhéus, Santa Cruz Cabrália).

Árvore 4-18 m alt. Estípulas não vistas. Pecíolo 10-80 mm compr., pulvino 1-5 mm compr.; raque 18 $100 \mathrm{~mm}$ compr., pubescente, segmentos interpinas 8 $27 \mathrm{~mm}$ compr.; nectário peciolar séssil, cilíndrico, inconspícuo, localizado da porção basal à distal do pecíolo, geralmente na porção mediana, ligeiramente menores na raque e nas pinas; pinas 3-7 pares, a basal 20-65 mm compr., a mediana 35-75 mm compr., a apical 37-115 $\mathrm{mm}$ compr., prolongamento da raque $1-$ $4 \mathrm{~mm}$ compr.; folíolos da pina basal 6-15 pares, da mediana 7-21 pares, da apical 7-21 pares, 7-8 × 2-4 $\mathrm{mm}$, os medianos oblongos a ovado-oblongos, ápice arredondado, margem assimétrica, os distais obovadooblongos, nervura principal central, margem lisa, esparsamente pubescente em ambas as faces, com tricomas brancos, curtos, ambas as superfícies lisas a reticuladas. Espigas 70-95 $\times 6-8 \mathrm{~mm}$, isoladas, geminadas ou fasciculadas; pedúnculo $8-25 \mathrm{~mm}$ compr., pubescente; brácteas 0,4-0,5 mm compr., persistentes ou tardiamente caducas, esparsamente pubescentes; botões elipsoides. Cálice 0,8-1 $\mathrm{mm}$ compr., lacínias ca. 0,2 mm compr., superfície externa pubescente ou glabra; corola 1,8-2,2 $\mathrm{mm}$ compr., glabra, tubo 0,2-0,4 $\mathrm{mm}$ compr., lobos 1,6-2 $\mathrm{mm}$ compr.; filetes 2,8-3,2 mm compr., vináceos; ovário 1,7-2 mm compr., 10-12-ovulado, estípite 0,8-1 mm compr, estilete 1,7-2,4 mm compr. Legumes 14-17 $\times$ 1,2-2,8 cm, estípite 0,6-1,5 cm compr. Sementes não vistas.

Ocorre nos estados do Espírito Santo, Minas Gerais, Rio de Janeiro e Bahia. G8, H8/9, I8: Mata Atlântica (floresta higrófila e de tabuleiro), a $50 \mathrm{~m}$ s.n.m. Floresce de novembro a março e frutifica a partir de abril.

Material selecionado - Belmonte, Estação Experimental Gregório Bondar, EGREB, 1551'48"S, 3852'58"W, 29 nov. 1987 (fr.), T.S. Santos 4347 (CEPEC, HST, K, MBM, NY); Ilhéus, Quadra I do CEPEC, Arboreto, 14\%46'48"S, 39 02'24"W, 11 abr. 1989 (fr.), L.A M. Silva et al. 2687 (ALCB, CEPEC, HUEFS, K); Itamaraju, fazenda Palmeira, 17 nov. 1971 (bot., fl.), M.T. Monteiro 23594 (HST); Porto Seguro, bifurcação à direita, no Km 17 da estrada que liga os Povoados de Vera Cruz (ex 41) e Vale Verde, 14\%46'59"S, 3901'59"W, 4 abr. 1979 (fr.), L.A.M. Silva et al. 345 (ALCB, CEPEC, HUEFS, K, NY); Potiraguá, Itaimbém, Ponto Chic, fazenda Raimundo Jorge Zumaeta, 1544'28"S, 39³5'24"W, 2 nov. 2014 (bot., fl.), H.C. Lima et al. 7902 (HUEFS, RB); Santa Cruz Cabrália, antiga rodovia que liga a Estação Ecológica PauBrasil (ESPAB) a Santa Cruz Cabrália, a $7 \mathrm{~km}$ NE da Estação, ca. $12 \mathrm{~km}$ a NW de Porto Seguro, 16 $16^{\prime} 41^{\prime \prime S}, 39^{\circ} 01^{\prime} 29^{\prime \prime W}, 28$ nov. 1979 (bot., f1.), S.A. Mori et al. 13048 (CEPEC, K, RB, NY).

Parapiptadenia pterosperma diferencia-se das demais espécies do gênero na Bahia pelos folíolos esparsamente pubescentes em ambas as faces (vs. folíolos glabros em $P$. blanchetii ou ocasionalmente com um tufo de tricomas na base da nervura principal em $P$. zehntneri e $P$. ilheusana). Assemelha-se a $P$. zenhtneri pelos folíolos oblongos ou ovado-oblongos, mas pode ser diferenciada pelo nectário localizado na porção mediana do pecíolo (vs. na porção basal do pecíolo, próximo ao pulvino, raramente na porção mediana, em P. zehntneri).

\section{Parapiptadenia zehntneri (Harms) M.P.Lima \&} H.C.Lima, Rodriguésia $36 \quad$ (60): 26.1984. Piptadenia zehntneri Harms, Notzbl. Bot. Gart. Berlin-Dahlem 8: 712. 1924.

Figuras 1I, 5 e 6A-G.

Nomes populares: angico (Jacobina), angico-bravo (Jacobina, Morro do Chapéu), angico-fava (Itiúba), angico-manjola (Glória), angico-roxo (Caetité), agambira (Barro Alto), faveiro (Pindaí), guanambirada-mata (Bom Jesus da Lapa), guanhambira (Barro Alto), inhambira (Jacobina), priquiteira (Caturama).

Arbusto ou árvore $1-12 \mathrm{~m}$ alt. Estípulas lanceoladas, caducas. Pecíolo 13-36 mm compr., pulvino 2-4 $\mathrm{mm}$ compr.; raque 26-90 $\mathrm{mm}$ compr., 


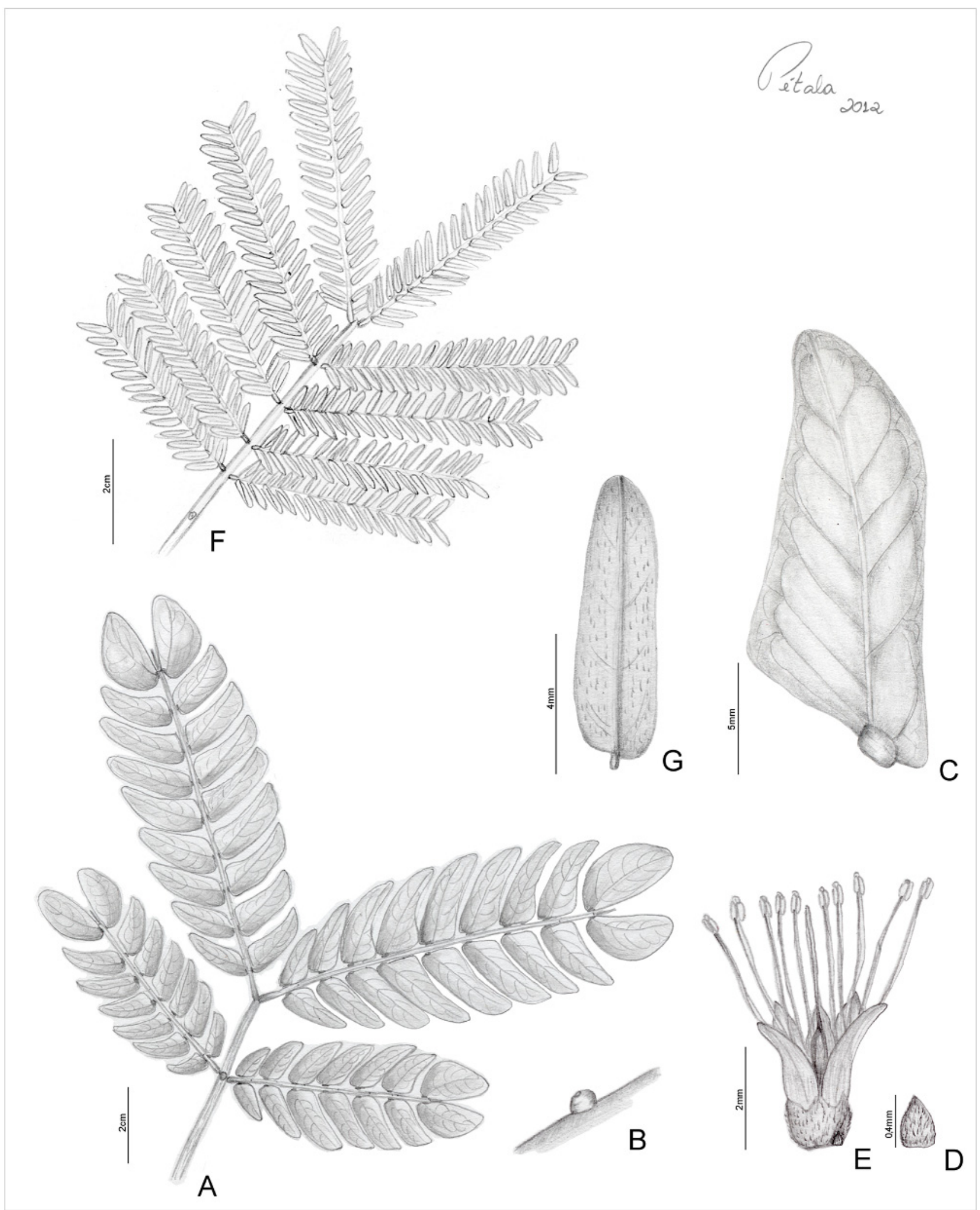

Figura 4. A-E. Parapiptadenia ilheusana: A- folha; B- nectário peciolar; C- folíolo, face adaxial; D- bráctea floral; E- flor. F, G. P. pterosperma: F- folha; G- folíolo, face adaxial. (A-E- Queiroz 13883; F, G- Monteiro 23666; por P.G. Ribeiro).

glabra, segmentos interpinas 13-28 mm compr.; nectário peciolar oblongo (plano ou côncavo), localizado na base do pecíolo, acima do pulvino ou abaixo do meio do pecíolo, discoides e ligeiramente menores na raque e nas pinas; pinas (1-)3-5 pares, a basal 25-60 mm compr., a mediana 40-70 mm compr., a apical $40-65 \mathrm{~mm}$ compr.; prolongamento da raque ca. $2 \mathrm{~mm}$ compr., linear; folíolos da pina basal (2)3-5 pares, da mediana 5-7 pares, da apical 6-7 pares, 12$26 \times 4-13 \mathrm{~mm}$, os medianos oblongos a ovado-oblongos, os distais obovais a romboides, ápice arredondado ou obtuso, base assimétrica, oblíqua e obtusa, nervura principal central, margem lisa, glabros em ambas as faces, exceto por um tufo de tricomas na 
base da nervura central, superfícies reticuladas. Espigas $38-75 \times 6-11 \mathrm{~mm}$, ramifloras ou somente axilares, pedúnculo $6-35 \mathrm{~mm}$ compr., glabro; brácteas $0,5-0,8 \mathrm{~mm}$, lineares, margem pubescente, caducas; botões elipsoides. Cálice $0,8-1,1 \mathrm{~mm}$ compr., lacínias ca. 0,2 $\mathrm{mm}$ compr., superfície externa com tricomas eretos esparsos; corola 2,2-3 mm compr., tubo $0,8-1$ mm compr., lacínias 1-2 mm compr., glabra; filetes 4$6 \mathrm{~mm}$ compr., vináceos; ovário 1-1,2 mm compr., 14 16-ovulado, estípite 1,8-2 mm compr., estilete 1,3-2 mm compr. Legumes 11-18 × 2,3-3 cm, estípite 1-2,5 $\mathrm{cm}$ compr. Sementes transverso-oblongas, núcleo seminífero $10-15 \times 3-8 \mathrm{~mm}$, ala 2-4 $\mathrm{mm}$ larg.

Ocorre no Nordeste do Brasil, em Alagoas, Pernambuco, Ceará, Paraíba e Bahia. B9, C8, D5, D6, D7, E5, E7, F3, F4, F5, G5: Caatinga (florestas e nanoflorestas estacionais deciduais, sobre solo arenoso, areias quartzosas ou afloramentos calcários), em altitudes de 39 a $892 \mathrm{~m}$. Floresce em outubro e novembro, apresentando frutos praticamente $\mathrm{o}$ ano todo.

Material selecionado - Andorinha, Cruzeiro, $10^{\circ} 20^{\prime} 08^{\prime \prime} \mathrm{S}$, 3950'08"W, 6 jan. 2009 (bot., fl.), J. Antunes 73 (HVASF); Barro Alto, Comunidade de Lagoa Funda, fazenda Lagoa Branca, $11^{\circ} 45^{\prime} 12^{\prime \prime S}, 41^{\circ} 50^{\prime} 08^{\prime \prime W}, 8$ abr. 2002 (fr.), T.S. Nunes et al. 907, 917(HUEFS, MBM);ib., 8 abr. 2002 (est.), T.S. Nunes et al. 919, 925 (HUEFS, MBM); Bom Jesus da Lapa, BA-160, 13³0'24"S ,

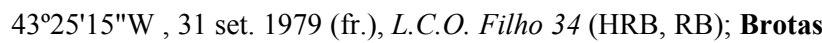
de Macaúba, comunidade Jatobá, $12^{\circ} 14^{\prime} 35^{\prime \prime} \mathrm{S}, 42^{\circ} 31^{\prime \prime} 59^{\prime \prime} \mathrm{W}, 21$ jul. 2000 (fr.), N.R.S. Cruz et al. 8 (HUEFS); Caém, Piemonte da Diamantina, $11^{\circ} 07^{\prime} 01^{\prime \prime S}, 40^{\circ} 08^{\prime} 26^{\prime \prime} \mathrm{W}, 5$ ago. 2001 (fr.), D.M. Loureiro et al. 261 (ALCB, MBM); Caetité, estrada de acesso entre os povoados de Juazeiro, Caetité e São Timóteo, Livramento Nossa

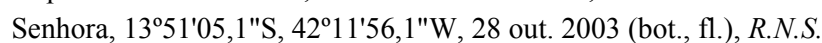
Pereira et al. 110 (MBM, IPA); Caturama, Caieiras, 131' $27^{\prime \prime S}$, 42 $2^{\circ} 3^{\prime} 32^{\prime \prime} \mathrm{W}, 5$ set. 2007 (est.), A.A. Conceição et al. 2387 (HUEFS); Coribe, estrada de São Felix do Coribe para Coribe, região da microbacia do rio Formoso, 44 $15^{\circ} 28^{\prime \prime} \mathrm{W}, 13^{\circ} 41^{\prime} 28^{\prime \prime} \mathrm{S}, 7$ jun. 2007 (fr.), M.M.M. Lopes et al. 1312 (CEPEC, HUEFS); Curaçá, estrada para a Comunidade de Patamuté, 09²16 23 "S, 39³2'36"W, 20 out. 2010 (bot., fr.), E. Melo et al. 8701 (HUEFS); Glória, Brejo do Burgo, 28 nov. 1992 (bot., fl., fr.), F.P. Bandeira \& M.L. Guedes 82 (ALCB, HRB, HUEFS, JPB, RB, UFRN); Ibitiara, estrada para Mucambo, $12^{\circ} 38^{\prime} 55^{\prime \prime} \mathrm{S}, 42^{\circ} 17^{\prime} 50^{\prime \prime} \mathrm{W}, 11$ out 2007 (bot., fl.), A.A. Conceição et al. 2536 (ALCB, HUEFS); Irecê, Barra do Mendes, Barragem de São Bento, $11^{\circ} 48^{\prime} 44^{\prime \prime} \mathrm{S}, 42^{\circ} 05^{\prime} 24^{\prime \prime} \mathrm{W}$, 25 out. 2009 (bot., fl., fr.), M.L. Guedes et al. 16085 (ALCB, HUEFS); Itiúba, estrada Itiúba-Picos, cerca de $5 \mathrm{~km}$ de Itiúba, Fazenda Experimental da EPABA, SC.24-Y-B, 10³8'58"S, 3952'33"W, 17 ago. 2002 (fr.), L.P. Queiroz et al. 7356 (HUEFS, HUESB, UEC, RB); ib., $6 \mathrm{~km}$ a E da cidade, Serra de Itiúba, $39^{\circ} 48^{\prime} \mathrm{W}, 10^{\circ} 41^{\prime} \mathrm{S}, 19$ fev. 1974 (bot., fl.) R.M. Harley 16198 (CEPEC, IPA, K, NY, RB); Jacobina, Tabua, $11^{\circ} 16^{\prime} \mathrm{S}, 41^{\circ} 06^{\prime} \mathrm{W}, 26$ ago. 1981 (fr.), R.P. Orlandi 453 (ALCB, HRB, K, NY, RB); Juazeiro, Mangas, povoado de Junco, 5 jul. 2012 (fr.), C.T.V. Martins \& J.T.L. Santos 228C (HUEFS, HSTA); Monte Santo, fazenda Pedra d'água, 10²2'36"S, 39²5'31"W, 31 mar. 2000 (fr.), N.G. Jesus et al. 922 (CEN, CEPEC, HUEFS); Morro do Chapéu, APA Gruta dos Brejões/Vereda do Romão Gramacho, 1 out. 2009 (bot. e fl.), R.F. Machado 383 (HUEFS); 31 out. 2009 (bot., fl.),

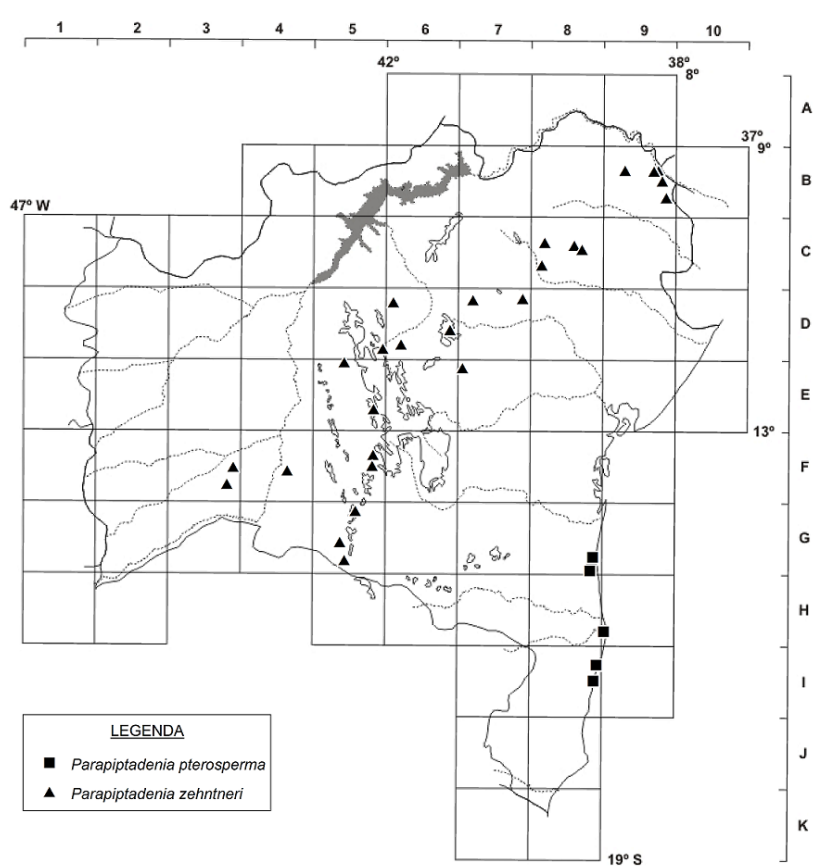

Figura 5. Mapa de distribuição de Parapiptadenia pterosperma e $P$. zehntneri no estado da Bahia.

R.F. Machado 336 (HUEFS); Paramirim, caminho CaturamaMateus, 131' $50^{\prime \prime S}, 42^{\circ} 14^{\prime} 44^{\prime \prime S}, 28$ abr. 2007 (fr.), A.A. Conceição et al. 1884 (HUEFS); Paulo Afonso, ca. $20 \mathrm{~km} \mathrm{~S}$ de Paulo Afonso, na BR-110, 09² $28^{\prime} \mathrm{S}, 38^{\circ} 12^{\prime} \mathrm{W}, 19$ dez. 1993 (fr.), L.P. Queiroz \& N.S. Nascimento 3727 (CEPEC, HUEFS, MBM, NY); Pindaí, entre Guanambi e Tanque, $14^{\circ} 19^{\prime} \mathrm{S}, 42^{\circ} 42^{\prime} \mathrm{W}, 16$ mar. 1981 (fr.), G.C.P. Pinto 171 (CEPEC, HRB, RB); Rio de Contas, ca. $3 \mathrm{~km}$ SE de Rio de Contas, na estrada para Livramento de Nossa Senhora,

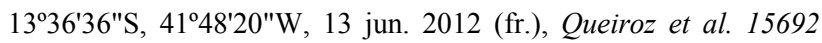
(HUEFS); Santa Brígida, Fazenda do Sr. José Alves, 09²' 51 "S, 38 08'44"W, 28 nov. 2009 (bot., fl.), E. Melo et al. 7266 (ALCB, HUEFS); São Félix do Coribe, ca. 7,6 km S de São Félix do Coribe, na estrada para Alagoinhas, $13^{\circ} 27^{\prime} 20^{\prime \prime S}, 44^{\circ} 10^{\prime} 16^{\prime \prime} \mathrm{W}, 13$ out. 2005 (fr.), L.P. Queiroz \& J.G. Carvalho-Sobrinho 10974

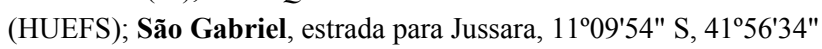
W, 25 out. 2009 (bot., fl.), E. Melo et al. 6948 (ALCB, HUEFS); Urandi, Serra Geral, cabeceira do rio Raízes, 14\%46'38"S, 42³5'35"W, 4 ago. 2009 (fr.), M.L. Guedes et al. 15814 (ALCB, HUEFS); Utinga, São Roque, 1204'59"S, 40 $58^{\circ} 59$ "W, 10 abr. 1986 (fr.), H.P. Bautista \& A.C. Sarmento 1103 (HUEFS, HRB, RB).

Parapiptadenia zehntneri pode ser confundida com P. pterosperma (ver comentários naquela espécie). Também pode ser confundida com Plathymenia reticulata Benth. pelo formato semelhante dos folíolos, diferenciando-se vegetativamente daquela espécie pelo número de folíolos por pina (5-7 vs. 11-16 em Plathymenia reticulata), disposição oposta dos folíolos (vs. alterna), pinas ligeiramente crescentes para o ápice (vs. equilongas) e nervuras secundárias oblíquas em relação à principal (vs. perpendiculares ou quase). Quando fértil, diferencia-se de Plathymenia. reticulata também pelas flores sésseis com estames vináceos (vs. pediceladas com estames brancos ou creme) e pelo fruto legume (vs. criptolomento, com endocarpo formando envelopes monospérmicos). 


\section{AGRADECIMENTOS}

Os autores agradecem aos curadores dos herbários ALCB, BAH, BHCB, CEN, CEPEC, F, HRB, HST, HSTA, HUESB, HUEFS, HVASF, IBGE, IPA, JPB, K,
MBM, NY, PEUFR, R, RB, SP, SPF, UEC, UFRN e UB, pela recepção e empréstimo de materiais. Ao PPGBot-UEFS, pela infraestrutura; ao Programa de Pesquisa em Biodiversidade do Semiárido (PPBio Semiárido - MCT/CNPq) e ao Sistema Nacional de

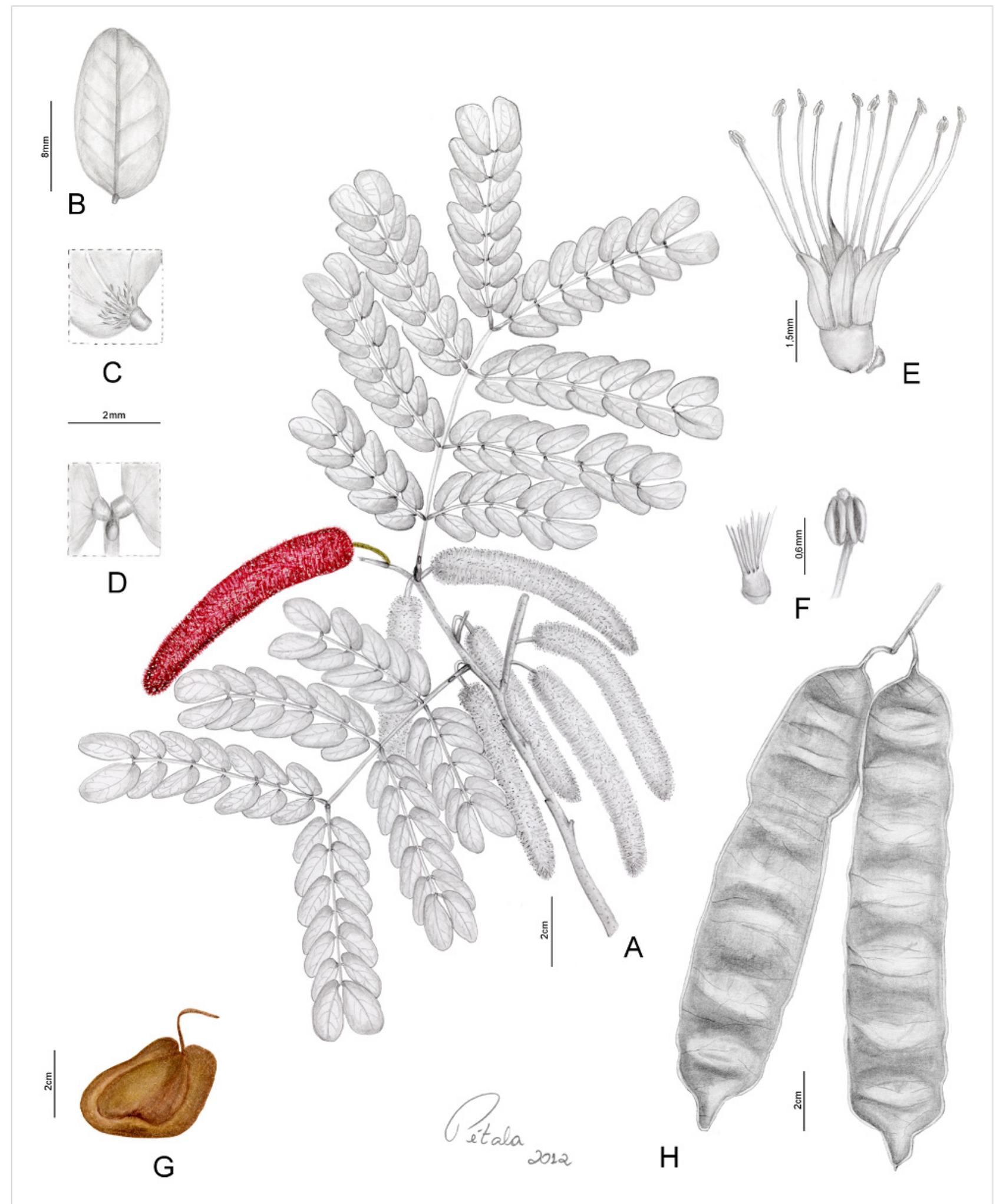

Figura 6. A-G. Parapiptadenia zehntneri: A- ramo com folhas e inflorescências; B- folíolo distal, face adaxial; C- detalhe da face abaxial do folíolo mostrando tufo de tricomas na base da nervura; D- nectário imediatamente abaixo da inserção do par distal de folíolos; E- flor em antese total; F- estame, mostrando a base com os filetes levemente concrescidos (à esquerda) e ápice evidenciando a antera com a glândula no ápice (à direita); G- semente alada. H. P pterosperma: legumes. (A-F- Conceição 2536; G- Lopes 1312; H- Monteiro 23666; por P.G. Ribeiro). 
Pesquisa em Biodiversidade (SISBIOTA - CNPq 563084/2010-3 e FAPESB PES0053/2011), bem como aos projetos PRONEX (FAPESB PNX0014/2009), PROTAX (CNPq 562354/2010-7) e REFLORA (CNPq 563546/2010-7/FAPESB PES0054/2011), pelo suporte financeiro; aos colegas e funcionários do HUEFS (especialmente Teo, Zezé e Elaine), pelo auxílio em diversas fases do trabalho; à $\mathrm{Dr}^{\mathrm{a}}$. Ana Maria Giullieti e à $\mathrm{Dr}^{\mathrm{a}}$. Daniela Carneiro Torres, pela leitura minuciosa da dissertação na qual se baseou o tratamento; ao Dr. Marlon Machado pela montagem e edição das pranchas das ilustrações botânicas, e à Cássia e ao Henrique pela revisão das pranchas; ao Leilton Damascena pela confecção dos mapas de distribuição geográfica; à Carolina Ribeiro pela organização do banco de dados; ao Dr. Domingos Cardoso por ceder fotos para este trabalho e por contribuir com informações sobre as espécies estudadas; à $\mathrm{Dr}^{\mathrm{a}}$ Efigenia de Melo por ceder fotos para este trabalho e pelo apoio na coleta de $P$. blanchetii; à $\mathrm{Dr}^{\mathrm{a}}$ Évia R. Souza, por sugestões e contribuições para este trabalho; aos colegas Heitor S. Liuth, James Lucas, Lukas Daneu, Maciele Macedo, Ricardo Perdiz e Thiago Araújo, pelo apoio nas coletas da região de Ilhéus, em especial ao Dr. Andre Amorim (CEPEC). Ao amigo Fábio Espírito-Santo, pelo apoio nas visitas aos herbários, e à Adelina, Ana Paula, Eloína, Letieres e Priscila, pelo auxílio na finalização da Flora. A primeira autora teve auxílio também do Projeto REFLORA, em Kew Gardens, e Rupert Barneby Award, no New York Botanical Gardens. Os autores agradecem aos pareceristas Leonardo Maurici Borges e Juliana Santos Silva pelas sugestões e correções no manuscrito. Este trabalho é parte da dissertação da primeira autora PGR, desenvolvida no PPGBot/UEFS, com bolsa categoria GM CNPq (processo 130515/20108). LPQ é bolsista de produtividade do CNPq.

\section{REFERÊNCIAS}

Almeida, P.G.C.; Souza, E.R. \& Queiroz, L.P. 2015. Flora da Bahia: Leguminosae - Aliança Chloroleucon (Mimosoideae: Ingeae). Sitientibus, série Ciências Biológicas 15: http://dx.doi.org/10.13102/scb289.

BFG [The Brazil Flora Group] 2015. Growing knowledge: an overview of Seed Plant diversity in Brazil. Rodriguésia 66(4): 1085-1113.
Bruneau, A.; Mercure, M.; Lewis, G.P. \& Herendeen P.S. 2008. Phylogenetic patterns and diversification in the caesalpinioid legumes. Canadian Journal of Botany 86: 697-718.

Lewis, G.P. 1987. Legumes of Bahia. Royal Botanic Gardens, Kew.

Lewis, G.P. 1994. A new species of Parapiptadenia (Leguminosae: Mimosoideae) from Brazil. Kew Bulletin 49: 99-101.

Lewis, G.P. \& Elias, T.S. 1981. Mimoseae. In: R.M. Pohill \& P.H. Raven (eds), Advances in Legume Systematics. Vol. 1. Royal Botanic Gardens, Kew, p. 155-168.

Lewis, G.P.; Schrire, B.; Mckinder, B. \& Lock, M. 2005. Legumes of the World. Royal Botanic Gardens, Kew, p. 162183.

Lima, M.P.M. \& Lima, H.C. 1984. Parapiptadenia Brenan (Leguminosae - Mimosoideae) - estudos taxonômicos das espécies brasileiras. Rodriguésia 36(60): 23-30.

LPWG [Legume Phylogeny Working Group] 2013. Legume phylogeny and classification in the $21^{\text {st }}$ century: progress, prospects and lessons for other species-rich clades. Taxon 62: 217-248.

Luckow, M.; Miller, J.T.; Murphy, D.J \& Livshultz, T. 2003. A phylogenetic analysis of the Mimosoideae (Leguminosae) based on chloroplast DNA sequence data. In: B.B. Klitgard \& A. Bruneau (eds), Advances in Legume Systematics. Vol. 10. Royal Botanic Gardens, Kew, p. 197-220.

Luckow, M. 2005. Tribe Mimoseae. In: G.P. Lewis, B. Schrire, B. Mckinder \& M. Lock. (eds), Legumes of the World. Royal Botanic Gardens, Kew, p. 162-183.

Queiroz, L.P. 2009. Leguminosas da Caatinga. Universidade Estadual de Feira de Santana, Feira de Santana.

Schrire, B.D.; Lavin, M. \& Lewis, G.P. 2005. Global distribution patterns of the Leguminosae: insights from recent phylogenies. In: I. Friis \& H. Balslev (eds), Plant diversity and complexity patterns: local, regional and global dimensions. Biologiske Shrifter 55: 375-422.

Snak, C. \& Queiroz, L.P. 2016. Flora da Bahia: Leguminosae Canavalia (Papilionoideae: Diocleae). Sitientibus, série Ciências Biológicas 16: http://dx.doi.org/10.13102/scb1136.

Souza, I.M.; Funch, L.S. \& Queiroz, L.P. 2016. Flora da Bahia: Leguminosae - Hymenaea (Caesalpinioideae: Detarieae). Sitientibus, série Ciências Biológicas 16: http://dx.doi.org/ $10.13102 / \mathrm{scb} 1092$

Wojciechowski, M.F.; Lavin, M. \& Sanderson, M.J. 2004. A phylogeny of legumes (Leguminosae) based on analysis of the plastid matk gene resolves many well-suported subclades within the family. American Journal of Botany 91:1846-1862.

\section{LISTA DE EXSICATAS}

Antunes, J. 73 (4); Araújo, A.P.P. 123 (1); Bandeira, F.P. 82 (4); Bautista, H.P. 757 (4), 1103 (4); Blanchet, J.S. 3295 (1); Cardoso, D. 1821 (4), 1918, 1943 (1); Carvalho, A.M. 587 (1); Carvalho-Sobrinho, J.G. 247, 1619 (4); Colaço, M. 64, 68 (4); Conceição, A.A. 1884, 2387, 2439, 2536 (4); Conceição, S.F. 3 (1); Cruz, N.R.S. 8 (4); Dias Martins, C.T.V. 228 C (4); Faria, S.M. 1833 (1); Farias, G.L. 223 (3); Filho, L.C.O. 34 (4); França, F. 2486 (1); Gross, E. 100, 181 (1); Grupo Pedra do Cavalo 1096 (1); Guedes, M.L. in PCD 2851 (1), 9100, 12065 (4), 14680 (1), 15814, 15881, 16085 (4), 17769, 17940 (1); Hage, J.L. 1645 (3), 2275 (1); Harley, R.M. 16198 (4); Jesus, N.G. 922 (4); Lemos, M.J.S. 56 (1); Lewis, G.P. 1963 (3); Lima, H.C. 7902 (3); Lopes, M.M.M. 1312 (4); Loureiro, D.M. 261 (4); Lucca, C.F. 16 (1); Machado, R.F. 336, 383, 513, 547, 566, 625 (4); Matos, A.O. 15 (1); Martins, C.T.V. 228 C (4); Melo, E. 1410 (1), 6948, 7266, 8701 (4); Monteiro, M.T. 23594, 23666 (3); Mori, S.A. 13048 (3); Nunes, T.S. 632, 907, 917, 919, 925 (4); Nascimento, F.H.F. 1162 (1); 1617 (4); Orlandi, R.P. 453 (4); Pereira, B.A.S. 3757 (4); Pereira, R.N.S. 110 (4); Pinto, G.C.P. 6 (1), 171 (4), 174, 328, 644 (1); Queiroz, L.P. 1038 (1), 3727, 4565, 4627, 6540, 7356, 10974, 12696 (4), 13883 (2), 15358, 15366, 15369, 15512 (1), 15692 (4); 
Ribeiro, T. 190 (1); Riedel, L. 2106 (1); Santana, D.L. 586 (1); Santos, F.S. 662 (3); Santos, T.S. 3850 (3), 3857,4303 (2), 4347 (3); Silva, F.S. 1 (1); Silva, L.A.M. 345, 2687 (3); Souza, V.C. 339 (4); Thomas, W.W. 12372 (1). 


\section{APÊNDICE \\ Material suplementar fornecido pelos autores (não editorado)}

\section{Lista completa de material examinado}

\subsection{Parapiptadenia blanchetii (Benth.) Vaz \& M.P.Lima}

Material examinado: Amargosa, s.1., 26 mar.1980 (fr.), G.C.P. Pinto 174 (CEPEC, HRB, IPA). Anguera, Fazenda Retiro, ca. 18 Km de Feira de Santana na Estrada do Feijão sentido Ipirá, 1209'42" S, $39^{\circ} 11^{\prime} 02^{\prime \prime} \mathrm{W}, 300-600$ m, 22 mai. 2007 (est.), ib., 22 mai 2007 (est.), D. Cardoso \& R.M. Santos 1943 D. Cardoso \& R.M. Santos 1918, 1943 (HUEFS). Cachoeira, Trecho superior do Rio Jacuípe, Vale dos Rios Paraguaçu e Jacuípe, 12³2' S, 3905' W, 40-120 m, fev. 1981 (bot. e fl.), Grupo Pedra do Cavalo 1096 (ALCB, BAH, CEPEC, HRB,

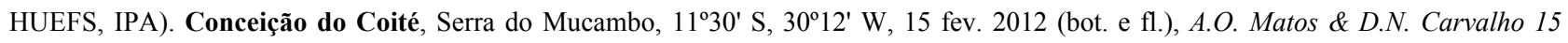
(HUEFS). Cruz das Almas, s.1., dez. 1950 (bot. e f1.), G.C.P. Pinto 644 (ALCB, BAH, RB); s.1., out. 1951 (bot. e fl.) G.C.P. Pinto 328 (ALCB). Dom Macedo Costa, Fazenda Mocambo, 25 set. 1982 (bot. e fl.), M.J.S. Lemos 56 (HUEFS). Elísio Medrado, Recôncavo sul, Serra da Jibóia, 12 $51^{\circ}$ S, 39² $28^{\prime} \mathrm{W}, 8$ fev. 2011 (est.), M.L. Guedes et al. 17940 (ALCB). Feira de Santana, Distrito de Ipuaçu (João Durval), 12 $13^{\prime} 54^{\prime \prime ~ S, ~ 3904 ' 35 " ~ W, ~ 200-300 ~ m, ~} 14$ set. 2004 (est.), S.F. Conceição et al. 3 (HUEFS); Distrito de Ipuaçu, Inselberg, Monte Alto, Plateau 3, 12 $13^{\circ} 53^{\prime \prime} \mathrm{S}, 39^{\circ} 04^{\prime} 38^{\prime \prime W}, 30$ set. 2003 (bot. e fl.), C.F. Lucca et al. 16 (MBM, HUEFS); Rod. Feira/Rio de Janeiro, Km 8, margem do rio Jacuipe, 19 fev. 1981 (bot. e fl.), A.M. de Carvalho et al. 587(CEPEC, HRB, RB); BA-052, Km 04 W de Feira de Santana, 12 $16^{\prime} 15^{\prime \prime S}, 39^{\circ} 03^{\prime} 34^{\prime \prime} \mathrm{W}, 13$ nov. 1986 (bot.), L.P. Queiroz \& M.J.S. Lemos 1038 (HUEFS); Paraguaçu, Bairro Caroá, $12^{\circ} 16^{\prime S}$, $38^{\circ} 58^{\prime}$ W, 25 fev. 2002 (fr.), D. L. Santana 586 (ALCB, CEPEC). Inhambupe, s.1., 03 jan. 1981 (bot. e fl.), G.C.P. Pinto 6 (CEPEC, HRB, HUEFS, IPA, MBM). Itaju do Colônia, 7,5 Km southeast of Itaju do Colônia on road to Palmira, 1509'13"S, 39³9'27,6"W, ca. 250 m, 19 mar. 2001 (fr.), W.W. Thomas et al. 12372 (CEPEC, HUEFS, RB). Itatim, Morro do Agenor ou da Madeira, 12 $43^{\prime} \mathrm{S}, 39^{\circ} 42^{\prime} \mathrm{W}, 310-430 \mathrm{~m}$, 17 dez. 1995 (bot. e fl.), E. Melo et al. 1410 (BAH, HUEFS, UB); Recôncavo Sul, Trilha da Pedra Furada, 1242'S, $39^{\circ} 41^{\prime} W, 23$ mar. 2009 (fl.), M.L. Guedes 14680 (ALCB, EAC). Jacobina, Ramal a ca. $9 \mathrm{Km}$ na rodovia BA-052, $5 \mathrm{Km}$ ramal adentro para Riachão de Jacobina, 29

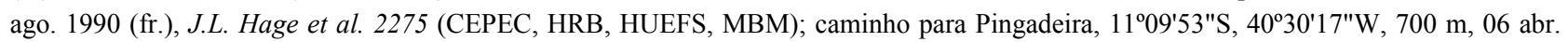
1996 (bot. e fl.), M.L. Guedes et al. in PCD 2851 (ALCB, HUEFS, SPF); Mata dos Bandeirantes (futura Reserva Biológica dos

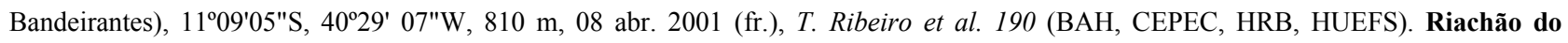
Jacuípe, Fazenda Sossego, a ca. $11 \mathrm{Km}$ da cidade, 12³2'S, 3905'W, 11 ago. 2002 (fr.), F.S. Silva 1 (HUEFS). Santa Terezinha, Recôncavo sul, 1250'59"S, 39²8'33"W, 816 m, 24 out. 2010 (fr.), M.L. Guedes 17769 (ALCB); Serra da Jibóia, 555 m, 20 fev.1998 (bot. e

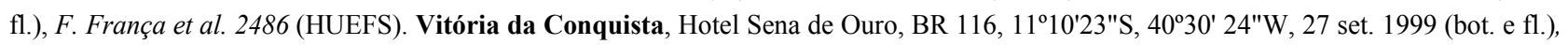
S.M. Faria et al. 1833 (RB). s. m., Mont. Org., 1831(fl.), L. Riedel 2106, com Luschnart 1831-1835 (NY), Serra da Jocobina, Blanchet 3295 (holótipo W, F, RB foto do tipo). s.m., Próximo a Jequié., 1359'10"S, 39³8'37"W, 26 out.1978 (fr.), A.P.P. de Araújo 123 (HRB, $\mathrm{RB})$.

\subsection{Parapiptadenia ilheusana G.P.Lewis}

Material examinado: Ilhéus, Área do CEPEC, Quadra H', km 22 da Rodovia Ilhéus/Itabuna, BR 415, 18 dez. 1986 (fl.), T.S. dos Santos 4303 (ALCB, CEPEC, HRB, HUEFS, K, MBM, NY, RB, SP,); ib., 4 abr. 1983(fr.), T. S. dos Santos 3857 (CEPEC, RB, K, NY). Itajú do Colônia, Fazenda Nova Esperança, ca. 13 Km de Ibicaraí, 1456'59"S, 39³7'37"W, 02 out. 2008 (bot., fl. e fr.), L.P. de Queiroz et al. 13883 (HUEFS).

\subsection{Parapiptadenia pterosperma (Benth.) Brenan}

Material examinado: Belmonte, Fazenda Brejinho, 24 abr. 1972 (fr.), M.T.Monteiro 23666 (HST); Área da Estaçao Experimental Gregorio Bondar, EGREB, 1551'48"S, $38^{\circ}{ }^{\circ} 52^{\prime} 58^{\prime \prime W}, 29$ nov. 1987(fr.), T.S. dos Santos 4347 (CEPEC, HST, K, MBM, NY). Ilhéus, Quadra I' do CEPEC, Arboreto, 1446'48" S, 3902'24" W, 11 abr. 1989 (fr.), L.A M. Silva et al. 2687 (ALCB, CEPEC, HUEFS, K); Área do CEPEC (Centro de Pesquisas do Cacau), km 22 da Rodovia Ilhéus/Itabuna (BR 415), Quadra I' do CEPEC, 1446'48" S, 3902'24" W, 18 fev. 1982 (bot., fl. e fr.), J.L. Hage 1645 (CEPEC, K, RB, NY); Quadra I do CEPEC, 16 mar. 1983, T. S. dos Santos 3850 (CEPEC, K). Itamarajú, Fazenda Palmeira, 17 nov. 1971 (bot. e fl.), M.T.Monteiro 23594 (HST). Porto Seguro, Bifurcação à direita, no km 17 da estrada que liga os Povoados de Vera Cruz (ex 41) e Vale Verde, 1446'59"S, $39^{\circ} 01^{\prime} 59^{\prime \prime}$ W, 04 abr. 1979 (fr.), L. A. M. Silva et al. 345 (ALCB, CEPEC, HUEFS, K, NY); s.l., 25 out. 1988 (bot.), G.L. Farias 233 (CEN, K); Potiraguá, Itaimbém, Ponto Chic, Fazenda Raimundo Jorge Zumaeta, pasto com remanescentes de mata seca, 154'28"S, 39³5'24"W, 02 nov. 2014 (bot. e fl.), H. C. de Lima et al. 7902 (HUEFS, RB); Santa Cruz Cabrália, Antiga rodovia que liga a Estação Ecológica Pau-Brasil (ESPAB) a Sta. Cruz de Cabrália, a $7 \mathrm{~km}$ ao NE da Estação, cerca de $12 \mathrm{~km}$ ao NW de Porto Seguro, $16^{\circ} 16^{\prime} 41$ "S, $39^{\circ} 01^{\prime 2} 29^{\prime \prime W}, 28$ nov. 1979 (bot. e fl.), S. A. Mori et al. 13048 (CEPEC, K, NY, RB); Área da Estação Ecológica do Pau-Brasil (ESPAB), cerca de 16km a W de Porto Seguro, rod. BR 367 (Porto Seguro/Eunápolis), Arboreto da ESPAB, quadra n ${ }^{\circ} .017,16^{\circ} 23^{\prime} \mathrm{S}, 39^{\circ} 08^{\prime} \mathrm{W}, 20$ out. 1987 (est.), F. S. Santos 662 (CEPEC).

\subsection{Parapiptadenia zehntneri (Harms) M.P. Lima \& H.C. Lima}

Material examinado: Andorinha, Cruzeiro, 10²0'08"S, 3950'08"W, 06 jan. 2009 (bot. e fl.) J. Antunes 73 (HVASF) Barro Alto,

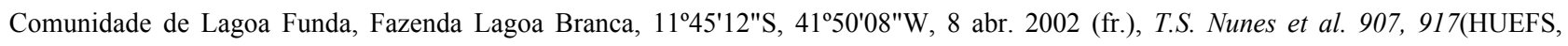
MBM); ib., 8 abr. 2002 (est.), T.S. Nunes et al. 919, 925 (HUEFS, MBM); Fazenda Lagoa Funda, 1145'19"S, 41'50'13"W, 27 nov. 2001 
(fr.), T.S. Nunes et al. 632 (HUEFS). Bom Jesus da Lapa, BA-160, 13³0'24"S 4325'15"W, 31 set. 1979 (fr.), L.C. O. Filho 34 (HRB, RB).

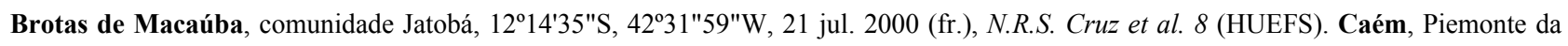

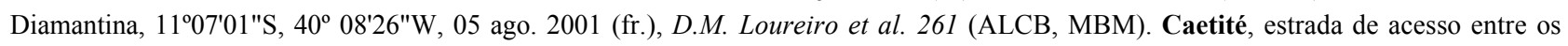

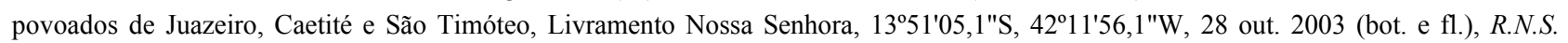

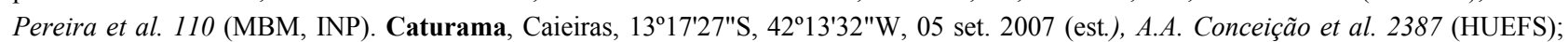
Mateus-Paramirim, 13º'19'21"S, 42¹2'13"W, 6 jul. 2007 (est.), A.A. Conceição et al. 2439 (HUEFS). Coribe, Estrada de São Felix do Coribe para Coribe, região da microbacia do rio Formoso, mudando para Rio Corrente, 22,4 Km, vilarejo Colônia, virar á esquerda, 5,1

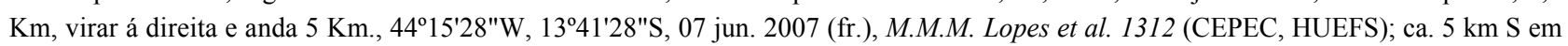
estrada de terra que cruza pequeno ramal que sai a $5,1 \mathrm{~km}$ E de Ponto d'água, a 24,4 km S de São Félix do Coribe na estrada para Coribe,

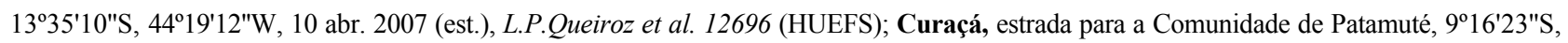
39³2'36"W , 20 out. 2010 (bot. e fr.), E. Melo et al. 8701 (HUEFS); Glória, Brejo do Burgo, 28 nov. 1992 (bot., fl. e fr.), F.P. Bandeira \&

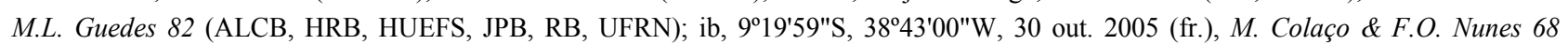
(HUEFS); ib., 29 out. 2005 (fr.), M. Colaço \& F.O. Nunes 64 (HUEFS); ca. 4 Km de Olhos d'Água de Souza, 9²0'37"S, 38²18'57"W, 26 abr. 2001 (fr.), L. P. de Queiroz et al. 6540 (ALCB, HUEFS). Ibitiara, estrada Ibitiara para Mucambo, 12³8'55"S, 42¹7'50"W, 11 out.

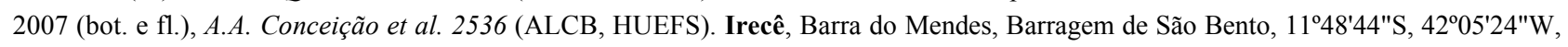
25 out. 2009 (bot., fl. e fr.), M.L. Guedes et al. 16085 (ALCB, HUEFS). Itiúba, estrada Itiúba-Picos, cerca de 5 km de Itiúba, Fazenda Experimental da EPABA. SC.24-Y-B, 10³8'58"S, 3952'33"W, 17 ago. 2002 (fr.), L. P. de Queiroz et al. 7356 (HUEFS, HUESB, UEC, RB); ca. 6,33 km de Itiúba, na estrada para Picos, 10³8'26"S, 3952'50"W, 19 abr. 2004 (fr.), J.G.de Carvalho-Sobrinho et al. 247 (HUEFS); Fazenda Experimental da EPABA, 26 mai. 1983 (fr.) H.P. Bautista \& G.C.P. Pinto 757 (HRB, MBM, RB); 6Km a E da cidade, Serra de Itiúba, about $6 \mathrm{~km}$ E of Itiuba on granitic hillaide, 3948'W, 10²41'S, 19 fev. 1974 (bot. e fl.) R. M. Harley 16198 (IPA, CEPEC, K, NY, RB); Jacobina, Localidade de Tabua, $11^{\circ} 16^{\prime} \mathrm{S}, 41^{\circ} 06^{\prime} \mathrm{W}, 26$ ago. 1981 (fr.), R.P. Orlandi 453 (ALCB, HRB, K, NY, RB); Piemonte da

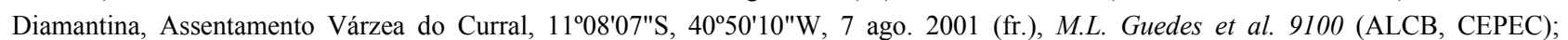
Juazeiro, Mangas povoado de Junco, 05 jul. 2012 (fr.), C. T. V. de Martins \& J. T. L. Santos 228C (HUEFS, HSTA); Monte Santo, Fazenda Pedra d'água, 10²2'36"S, 39²5'31"W, 31 mar. 2000 (fr.), N.G. Jesus et al. 922 (CEN, CEPEC, HUEFS) ;s.1., 10²6'S, $39^{\circ} 19^{\prime} \mathrm{W}, 11$ jan. 2006 (bot., fl. e fr.), M.L. Guedes et al. 12065(ALCB, CEPEC) ca. $11 \mathrm{~km}$ E de Monte Santo na estrada para Euclides da Cunha (Bazzo), s.d., 24 ago. 1996 (fr.), L.P.Queiroz \& N.S. Nascimento 4565 (HUEFS); ca. 14 km N de Monte Santo, na estrada para Uauá, s.d., 25 ago. 1996 (fr.), L.P.Queiroz \& N.S. Nascimento 4627 (HUEFS). Morro do Chapéu, Gruta dos Brejões, 20 fev. 2010 (fr.), R.F. Machado 513 (HUEFS); 21 fev. 2010 (fr.), R.F. Machado 547 (HUEFS); Gruta dos Brejões, APA Gruta dos Brejões/ Vereda do Romão Gramacho, APA com seus limites no município de Gabriel, Morro do Chapéu e João Dourado, 1 out. 2009 (bot. e fl.), R.F. Machado 383 (HUEFS) 31 out.

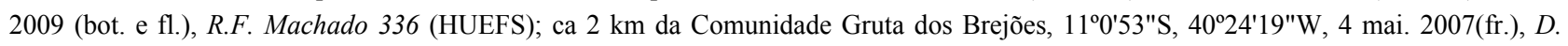

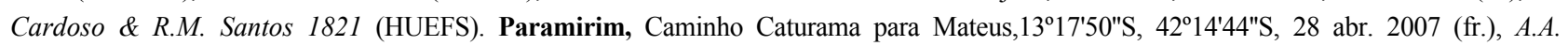
Conceição et al. 1884 (HUEFS). Paulo Afonso, ca. 20km S de Paulo Afonso, na BR-110, 9²8'59"S, 38¹2'W, 19 dez. 1993 (fr.), L.P. Queiroz

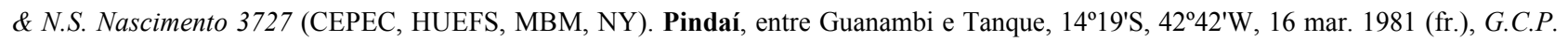
Pinto 171 (CEPEC, HRB, RB); Rio de Contas, ca. $3 \mathrm{~km}$ SE de Rio de Contas, na estrada para Livramento de Nossa Senhora, 13³6'36"S,

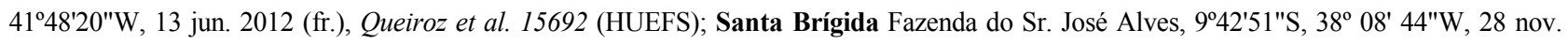
2009 (bot. e fl.), E. de Melo et al. 7266 (ALCB, HUEFS). São Félix do Coribe, ca. 7,6 Km S de São Félix do Coribe, na estrada para

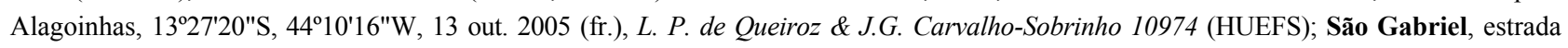

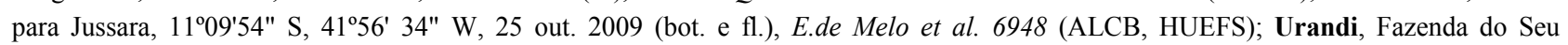

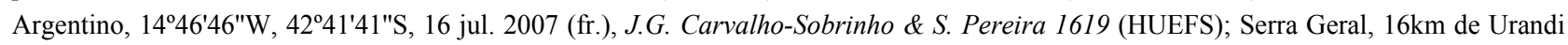

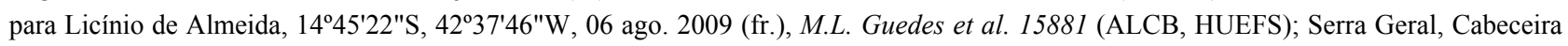
do Rio Raízes, 144' $38^{\prime \prime S}, 42^{\circ} 35^{\prime} 35^{\prime \prime W}, 4$ ago. 2009 (fr.), M.L. Guedes et al. 15814 (ALCB, HUEFS; Utinga, São Roque, 1204'59"S, 40 58'59"W, 10 abr. 1986 (fr.), H.P. Bautista \& A.C. Sarmento 1103 (HUEFS, HRB, RB). 